\title{
Experimental Study on Shear Behavior and Failure Mechanism of Bolted Heterogeneous Rock Joints under Different Anchorage Conditions
}

\author{
Xianzhen Cheng, ${ }^{1,2}$ Hengjie Luan $\mathbb{D}^{1,2}$ Yujing Jiang, ${ }^{1,2,3}$ Sunhao Zhang, ${ }^{1,2}$ \\ and Chuanyang Jia ${ }^{4}{ }^{4}$ \\ ${ }^{1}$ State Key Laboratory of Mining Disaster Prevention and Control Co-Founded by Shandong Province and the Ministry of Science \\ and Technology, Shandong University of Science and Technology, Qingdao 266590, China \\ ${ }^{2}$ College of Energy and Mining Engineering, Shandong University of Science and Technology, Qingdao 266590, China \\ ${ }^{3}$ Graduate School of Engineering, Nagasaki University, Nagasaki 852-8521, Japan \\ ${ }^{4}$ School of Civil Engineering and Architecture, Linyi University, China
}

Correspondence should be addressed to Hengjie Luan; luanjie0330@126.com

Received 2 April 2021; Accepted 23 May 2021; Published 7 June 2021

Academic Editor: Zhigang Tao

Copyright $\odot 2021$ Xianzhen Cheng et al. This is an open access article distributed under the Creative Commons Attribution License, which permits unrestricted use, distribution, and reproduction in any medium, provided the original work is properly cited.

Despite their frequent natural occurrence and engineering encounter, heterogeneous rock joints (rock joints with different lithological characters on both sides of the joint surface) have been studied much less systematically. To study the shear behavior and failure mechanism of bolted heterogeneous rock joints, laboratory tests were performed on the heterogeneous rock joints having different joint roughness coefficients (JRC) under different anchorage conditions. The results indicate that shear strength increases with the increase of JRC, showing exponential growth. Under the same roughness, the shear strengths of rock joints from large to small are fully grouted, end anchorage, and without anchorage. The mechanical characteristics of the bolt and joint are poorly matched under the end anchorage condition, which is easy to cause these two to be broken one by one. Under fully grouted, the extrusion force caused by the rock bolt will diffuse around the anchorage agent and will not cause partial continuous damage. The surface damage of heterogeneous rock joints increases with the increase of JRC and presents obvious heterogeneous characteristics. The shear dislocation between the blocks under shear load results in the interaction between the bolt and surrounding media. Under the action of shear force, the bolt body produced both axial and transverse deformation, which leads to breakage of anchorage agent and rock mass. Rock bolt has a significant impact on the shear behavior of the anchorage system, and the damage of the rock bolt to rock mass should be considered in rock engineering reinforcement design.

\section{Introduction}

Rock joints are mechanical discontinuities developed due to varied geological processes [1]. These discontinuities are present in the form of joints, faults, bedding planes, foliations, or other recurrent planar fractures in the rock mass [2-12]. In general, the stability of rock mass is dominantly controlled by the shear strength of discontinuities $[13,14]$. Numerous of rock engineering applications such as civil and mining engineering projects have proved that the instability and integral failure of the rock mass have great correlations with extensions and propagations of weak discontinuities [15]. The reinforcement for jointed rock mass using rock bolts has always been one of the most effective and economical geo-structural reinforcing technologies widely used in rock engineering projects for more than 100 years since 1913 in Germany [16-21]. However, instability of anchored rock mass caused by bolt failure often occurs [21-23]. Rock bolt failure in the field could be attributed to the tension (joint opening) or the shear along the joint $[17,22,24,25]$. Most rock bolt failure (Figure 1) is due to 
shearing loads under rock burst conditions or within high stress rock masses [26, 27].

The shear responses of bolted rock joints are complex and influenced by a series of factors related to rock masses, grout, and bolt, such as joint roughness, rock strength, grout properties, grout conditions, bolt properties, and bolt installation angles [26, 28-31]. Many studies have been carried out to investigate these influencing factors. Grasselli conducted large scale laboratory tests to study the influence of several parameters and compared the behavior of different types of bolts [32]. Jalalifar and Aziz carried out laboratory tests on five types of bolt to study the load transfer capacity and failure mechanism of a fully grouted bolt installed across a joint in shear [33]. Liu and Li conducted laboratory tests with different inclinations of the bolt to the joint plane [34]. Li et al. (2017) compared the shear behavior of fiber glass bolt, rock bolt, and cable bolt for the bolt contribution to bolted concrete surface shear strength and bolt failure mode [20]. Determination of the mechanical properties of rock joints is essential and prerequisite for understanding the mechanical behavior of jointed rock masses [35]. Wang et al. analyzed the macro-micromechanical response of a bolted jointed rock mass using the discrete element software PFC2D at different anchorage angles [36]. Meng et al. studied the shear behavior of concrete blocks reinforced by fully grouted bolts with different diameters [37]. Ma et al. proposed a simple analytical modeling of shear behaviors of rock bolts perpendicular to joints [26]. Wu et al. proposed a mathematical model to predict the shear behavior of rock bolt in different roughness conditions [38]. Wang et al. carried out shear tests on jointed specimens with four types of anchorage states under constant normal loading to study the shear behavior of the anchored rock joints [39]. From the introductions above, it can be seen that previous studies mainly focused on the shear behavior and failure mechanism of bolted homogeneous rock joints (rock joints with same lithological characters on both sides of the joint surface). However, heterogeneous rock joints are widely developed in nature rock mass, which is prone to induce to geological disasters, such as landslide in the reservoir area, layered compound roof collapse of roadway in coal mines. Additionally, heterogeneous rock joints are often encountered in rock engineering, as in the gravity dam and cemented paste backfill, rock socketed piles, and rock bolts [40]. It is unacceptable to ignore the influence of heterogeneity on the shear behavior of bolted rock joints. Few studies have been conducted on the shear behavior and failure mechanism of heterogeneous rock joints. Tian et al. performed a series of direct shear tests on cemented concrete-rock joints with smooth artificial interaction surfaces to investigate the shear behavior of cohesive interfaces [41]. Hussein et al. conducted an experimental study on the concrete-rock interface shear behavior [42]. Lin et al. performed a laboratory experiment to discover the changing regularity of the shear strength on the binary structural plane [43]. Gutiérrez et al. conducted a series of PFC2D numerical simulations of unbonded rock-concrete planar and saw-tooth triangular joints under $\mathrm{CNL}$ and CNS boundary conditions [40].

Although above works contributed to the understanding of the shear behavior of heterogeneous rock joints, the fact remains that it would be more interesting to have results on

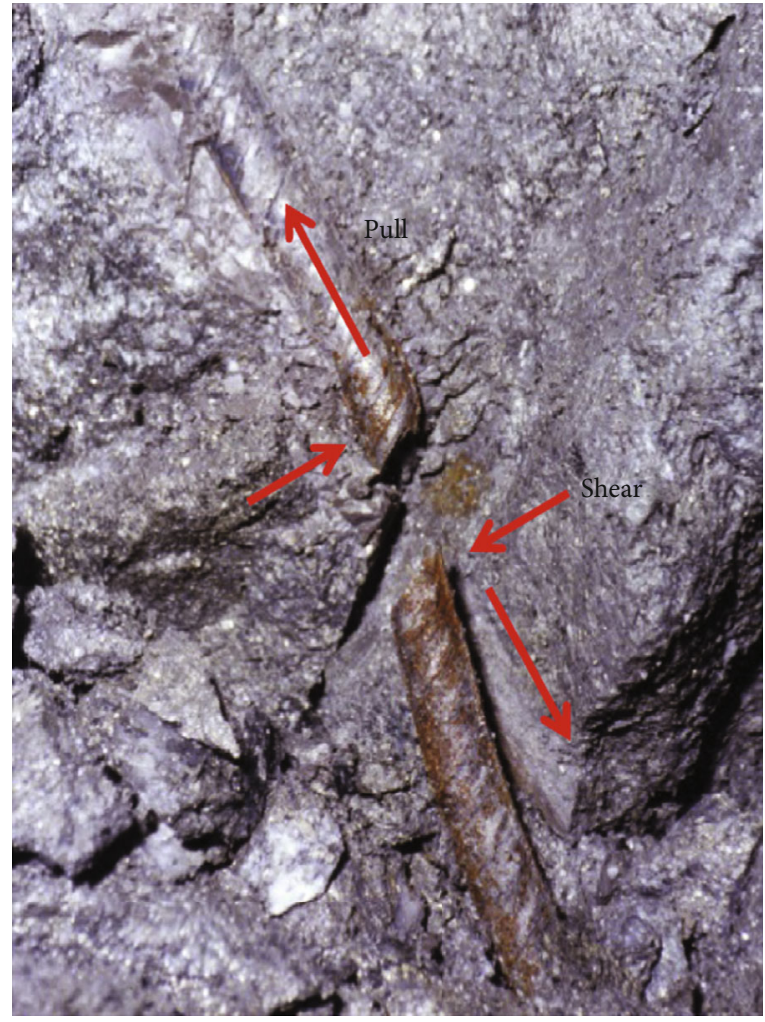

FIgURe 1: A rock bolt that failed in situ under both pull and shear loading [22].

the behaviors of bolted heterogeneous rock joints. But to the authors' knowledge, such a study has not been conducted to date. Hence, an attempt has been made in the present study to develop an understanding on assessing the shear behavior and failure mechanism of bolted heterogeneous rock joints through physical model tests in the laboratory.

\section{Experimental Methods}

2.1. Test Equipment. Direct shear tests under constant normal load (CNL) conditions were conducted using a JAW-600 coupled shear-flow machine (Figure 2) [44]. The shear and normal loads were applied by servo controlled hydraulic actuators. Furthermore, the machine has a design capacity of $600 \mathrm{KN}$ in both the shear (horizontal) and normal (vertical) directions and can test for both artificial and natural discontinuities. The shear and normal displacements are measured using linear variable differential transformers (LVDTs) in the horizontal and vertical directions. A maximum shear displacement of $40 \mathrm{~mm}$ and a shear rate in the range of $0.01 \sim 100 \mathrm{~mm} / \mathrm{min}$ are obtained [45]. The lower part of the block was fixed, and a shear force was applied to the upper part. The shear displacement, shear stress, normal displacement, and normal stress were recorded during experiment.

2.2. Specimen Preparation. In this paper, a number of blockyshaped artificial rock specimens with dimensions of $200 \times$ $100 \times 50 \mathrm{~mm}$ were casted in steel moulds (Figure 3(a)) with 


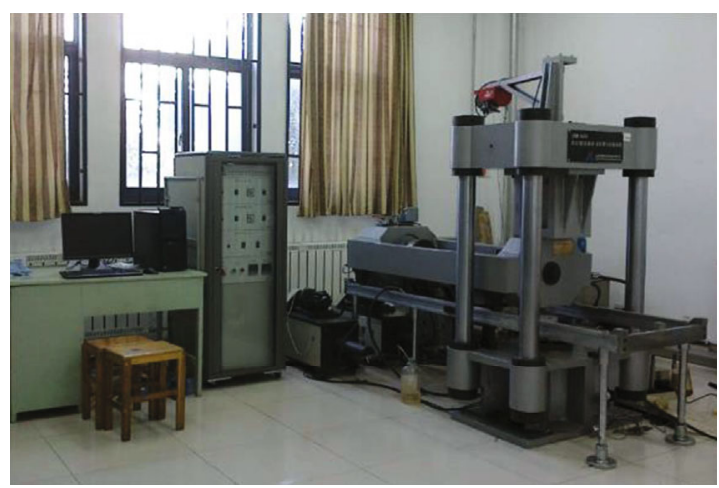

(a)

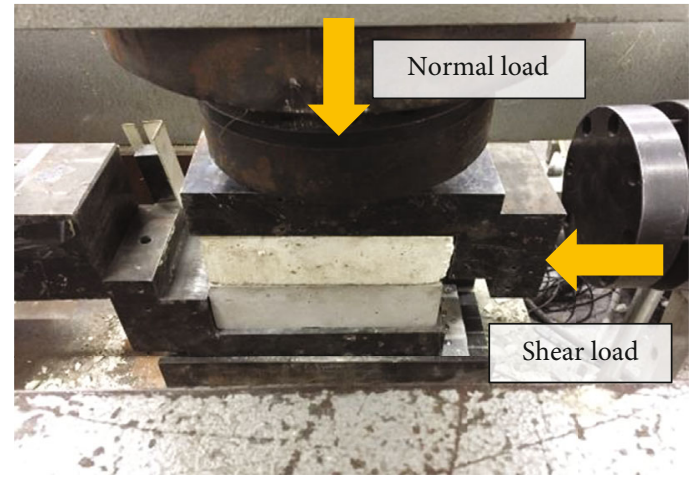

(b)

Figure 2: Arrangement of the shear test: (a) shear test system; (b) loading unit [44].

different JRC profiles proposed by Barton [35]. The curing process of artificial rock specimens was conducted at room temperature $\left(25^{\circ} \mathrm{C}\right)$ in a calorstat, and the curing time was 28 days. The heterogeneous rock joint was simulated by two artificial rock specimens with different mechanical property and having a pair of coupled joint surfaces, as shown in Figure 3(b). For the upper half artificial rock with low strength, the white cement-to-fine sand-to-water-to-water reducer ratio is $1: 1: 0.3: 0.005$. For the lower half artificial rock with high strength, the black cement-to-fine sand-towater-to-water reducer ratio is $1: 0.5: 0.25: 0.005$. The average uniaxial compressive strengths (UCS) of the upper half artificial rock and the lower half artificial rock are 22.97 $\mathrm{MPa}$ and $69.54 \mathrm{MPa}$, respectively. Such artificial rocks with these mechanical properties are within the variation scope in practical engineering.

For specimen needing anchorage, first, a borehole with a diameter of $10 \mathrm{~mm}$ was drilled to install the rock bolt [46]; next, the anchorage agent is injected into the corresponding position of the hole, and then, a bolt is inserted. The anchorage agent is injected at both ends of the anchor hole under end anchorage condition, and the anchorage agent is filled with holes under fully grouted condition. The rock bolts used in the anchor specimens are screws made of No. 45 steel, with a diameter of $6 \mathrm{~mm}$ and a length of $100 \mathrm{~mm}$, as shown in Figure 4(a); the anchorage agent is epoxy resin, as shown in Figure 4(b); the completed anchor specimen is shown in Figure 4(c). After 2 days of solidification at room temperature, the ideal anchoring effect can be achieved, and shear tests can be carried out.

2.3. Test Procedure. Laboratory shear tests were carried out to study the shear behavior and failure mechanism of bolted heterogeneous rock joints having different joint roughness under different anchorage conditions (without anchorage, end anchorage, and fully grouted). A total of eighteen shear experiments were conducted for three types of anchorage conditions. The JRC of each type are, $0,0 \sim 2,4 \sim 6,8 \sim 10$, $12 \sim 14$, and 16 18, respectively [47]. A constant normal stress of 1.0 MPa was applied on the top of the upper shear box during the shear process, and the shear load was applied laterally on the upper shear box. In order to simulate a quasistatic condition, the shear rate was set to $0.01 \mathrm{~mm} / \mathrm{min}$.

\section{Result Analysis}

3.1. Deformation and Strength Characteristics. The shear stress-displacement curves of rock-like heterogeneous joints under different anchorage conditions are, respectively, illustrated in Figures 5-7.

3.1.1. Without Anchorage. From the shear stress-shear displacement curves of heterogeneous joints under without anchorage condition in Figure 5, it can be seen that the variation trend is roughly similar. The heterogeneous rock joints experience four stages of deformation: compaction, a linear increase to the peak strength, a decrease in strength, and a gradual change in strength to the residual. The peak shear strength is obviously relevant to the JRC. The greater the JRC, the greater the peak strength.

3.1.2. End Anchorage. Comparing the curves of the joints without anchorage, from the shear stress-shear displacement curves under end anchorage condition in Figure 6, it can be seen that the curve variation characteristics under the two conditions are quite different. The shear stress-shear displacement curve under end anchorage condition is more complicated. There is an obvious "turning stage" in the process of stress increase. In addition, when the shear stress reaches stability, the corresponding shear displacement of end anchorage condition is much larger than that of the without anchorage.

3.1.3. Full-Length Anchorage. Comparing the curves of the joints without anchorage, from the shear stress-shear displacement curves under fully grouted condition in Figure 7 , it can be seen that their deformations have approximately the same stages. However, under the full-length anchorage condition, the displacement of shear stress reaching peak is much larger than that of under without anchorage condition.

3.1.4. Comparison of Different Anchorage Conditions. The typical shear stress versus displacement curves of rock joints under different anchorage conditions is presented in Figure 8 to show the differences of the shear stress curves. It indicates that the morphological characteristics of curves are significantly different under different anchorage conditions. 


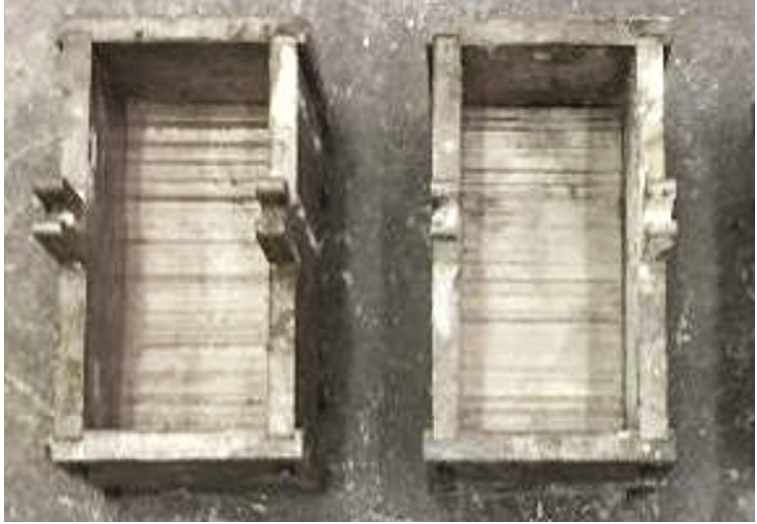

(a)

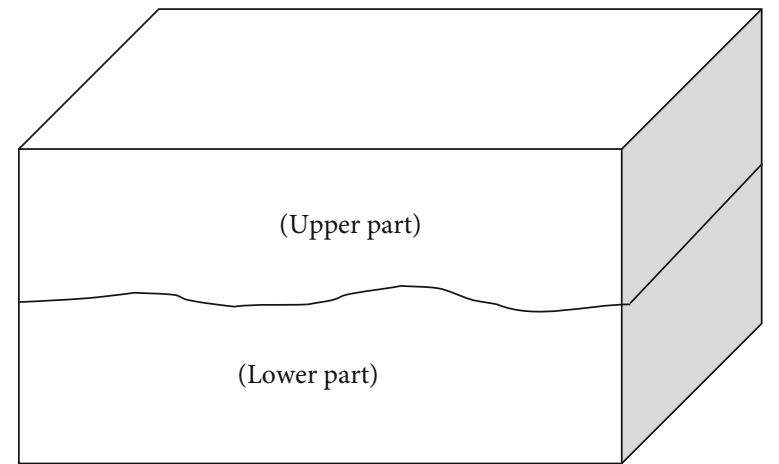

(b)

Figure 3: Preparation of rock-like joint specimen: (a) steel moulds; (b) schematic diagram of rock joint.

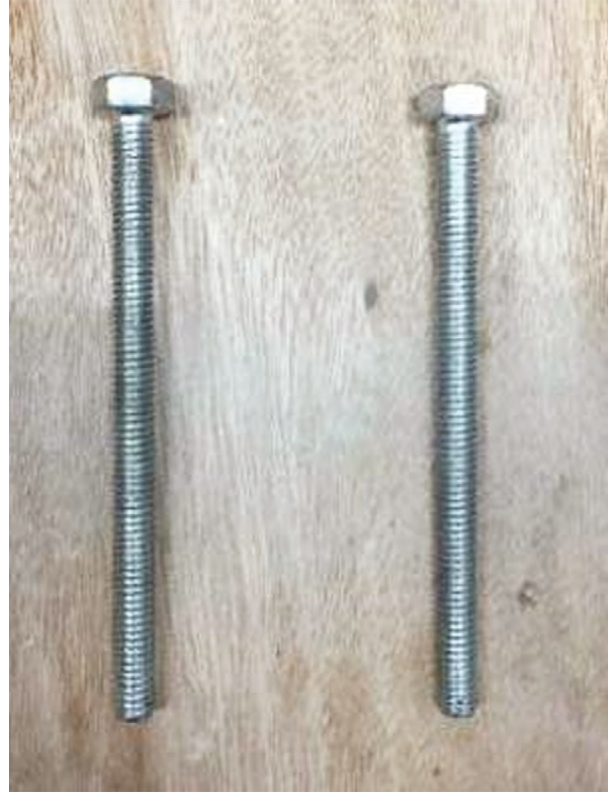

(a)

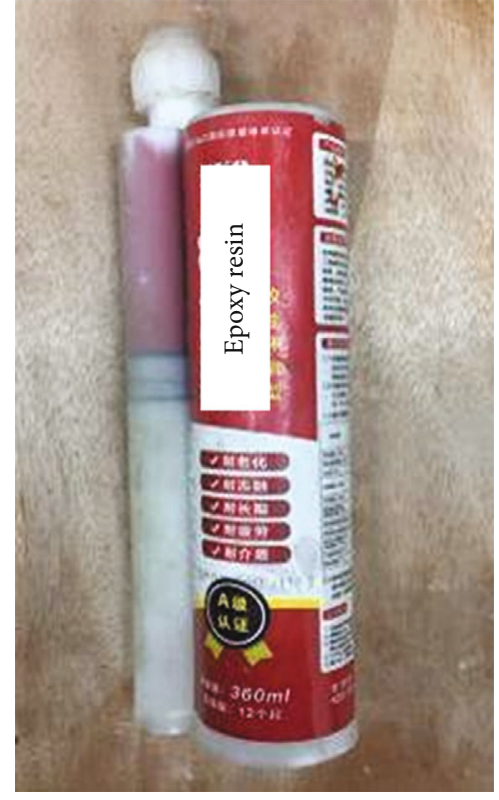

(b)

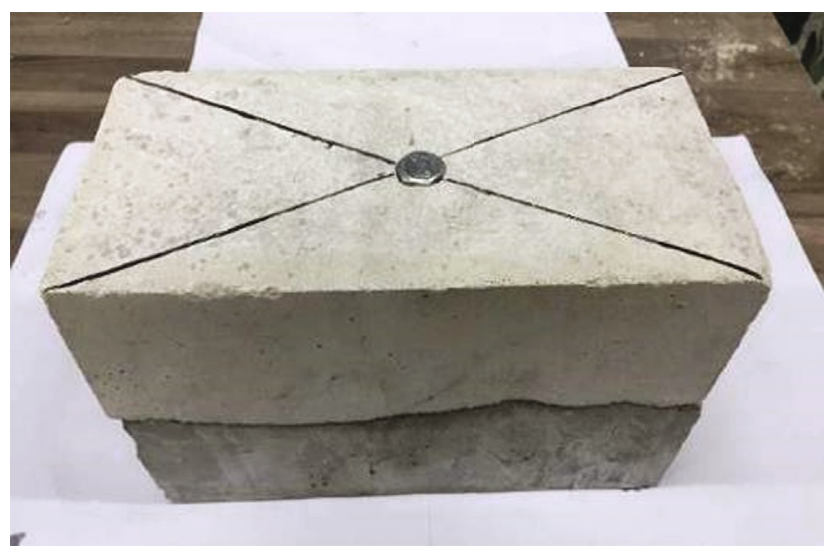

(c)

Figure 4: Preparation of anchorage specimen: (a) bolt; (b) anchorage agent; (c) specimen. 


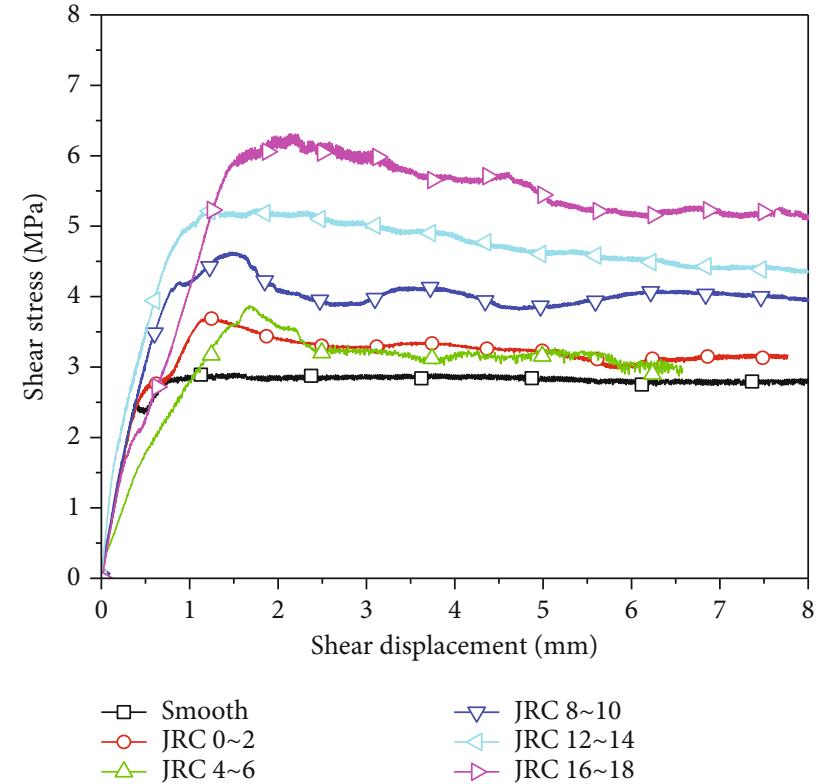

FIGURE 5: Curves of shear stress with respect to displacement under without anchorage condition.

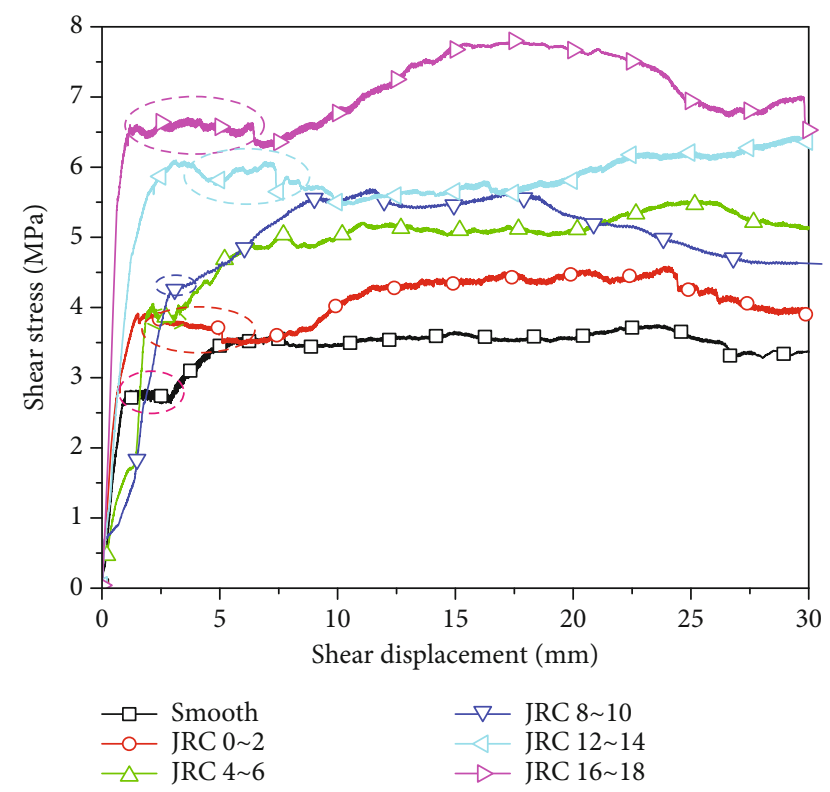

FIGURE 6: Curve of shear stress with respect to displacement under end anchorage condition.

Under the without anchorage condition, the shear stress increases linearly until the peak strength when shear displacement reaches $1 \sim 2 \mathrm{~mm}$. After that, the specimen reaches the ultimate load and loses its stability. Under the end anchorage condition, shear stress reaches a small peak first when shear displacement reaches $1 \sim 2 \mathrm{~mm}$ and then continues to increase after a slight drop. When the shear displacement is $5 \sim 10 \mathrm{~mm}$, the shear stress reaches the peak strength again. In this process, there is a "turning stage." Under the full-length anchorage condition, the shear stress

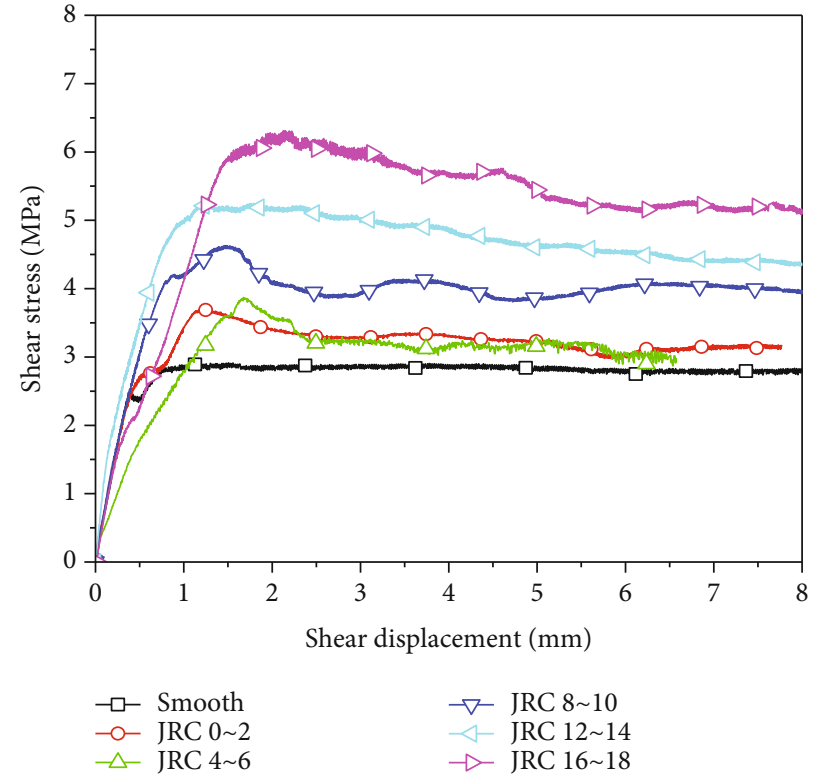

Figure 7: Curves of stress with respect to displacement under fulllength anchorage condition.

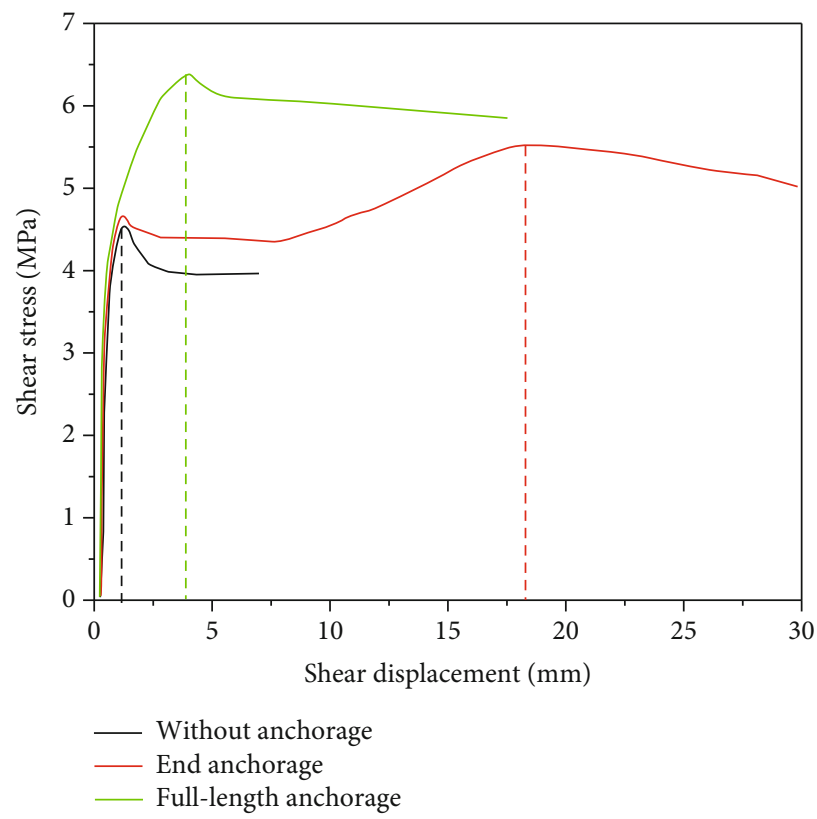

Figure 8: Typical curves of shear stress-shear displacement under different anchorage conditions.

increases continuously with the increase of shear displacement before reaching the yield point and reaches the peak value when the shear displacement is $3 \sim 6 \mathrm{~mm}$.

Generally, under the without anchorage condition, the rock joint bears the shear load only by its own shear capacity; under the end anchorage condition, the rock joint bears the shear load mainly by its own shear capacity because of there is a gap between rock bolt and anchor hole in the initial stage of shear, the rock bolt starts to play its role, and the shear capacity significantly enhanced when the shear displacement 
reaches a certain value; under the full-length anchorage condition, the rock joint immediately bears the shear load by the combination of bolt, rock mass, and anchorage agent because of the bolt is in close contact with the rock mass through the full-length anchorage agent; the "turning stage" of the end anchor specimen will not occur, which avoids the one by one breakage of the rock joint and the rock bolt. This is the reason why the full-length anchorage joints have higher ultimate load, faster resistance increase, longer plastic strength stage, and stronger residual shear resistance than the without anchorage and end anchorage joints.

3.2. Peak Shear Strength Characteristics. Table 1 lists the measured peak shear strength values of rough rock-like joints under different anchorage conditions. The relationships between shear strength and JRC and the fitting curves are presented in Figure 9. It can be seen that the variation trend of peak shear strength curves of rock-like joints under different anchorage conditions is similar. The shear strength of rock joints increases with the increase of JRC. For example, under the without anchorage condition, the shear strength of smooth rock joint is $2.91 \mathrm{MPa}$, and when the JCR increases to $0 \sim 2,4 \sim 6,8 \sim 10,12 \sim 14$, and 16 18, the shear strength increases to $3.70 \mathrm{MPa}, 3.87 \mathrm{MPa}, 4.63 \mathrm{MPa}, 5.27 \mathrm{MPa}$, and $6.31 \mathrm{MPa}$, respectively, with growth rates of $27 \%, 33 \%, 59 \%$, $81 \%$, and $117 \%$; under the end anchorage condition, the shear strength of smooth rock joint is $3.75 \mathrm{MPa}$, and when the JCR increases to $0 \sim 2,4 \sim 6,8 \sim 10,12 \sim 14$, and 16 18, the shear strength increases to $4.34 \mathrm{MPa}, 5.52 \mathrm{MPa}, 5.69 \mathrm{MPa}, 6.68$ $\mathrm{MPa}$, and $7.81 \mathrm{MPa}$, respectively, with growth rates of $16 \%$, $47 \%, 52 \%, 78 \%$, and $108 \%$; under the full-length anchorage condition, the shear strength of smooth rock joint is 4.02 $\mathrm{MPa}$, and when the JCR increases to $0 \sim 2,4 \sim 6,8 \sim 10$, $12 \sim 14$, and $16 \sim 18$, the shear strength increases to $5.31 \mathrm{MPa}$, $5.83 \mathrm{MPa}, 6.35 \mathrm{MPa}, 7.22 \mathrm{MPa}$, and $8.65 \mathrm{MPa}$, respectively, with growth rates of $32 \%, 45 \%, 58 \%, 80 \%$, and $115 \%$.

By fitting, the fitting relationship between the shear strength and JRC under different anchorage conditions is obtained, as shown in Equations (1)-(3). The fitting curves are exponential, and the fitting accuracy is high. With the increase of JRC, the growth rate of shear strength is gradually accelerated, showing exponential growth.

Without anchorage : $\tau=3.646+0.012$ JRC $^{1.924} R^{2}=0.9889$,

End anchorage : $\tau=4.335+0.040 \mathrm{JRC}^{1.586} R^{2}=0.9975$,

Full-length anchorage : $\tau=5.356+0.010 \mathrm{JRC}^{2.048} R^{2}=0.9956$.

Comparing the fitting curves of peak shear strength of joints shown in Figure 9, it can be seen that the peak shear strength of rock-like joints under the full-length anchorage condition is the largest, the second is under the end anchorage condition, and the smallest is under the without anchorage condition. In conclusion, without anchoring, the rock
TABle 1: Peak shear strength of rough rock-like joints under different anchorage conditions.

\begin{tabular}{lccc}
\hline \multirow{2}{*}{$\begin{array}{l}\text { Type of } \\
\text { joints }\end{array}$} & $\begin{array}{c}\text { Peak shear strength (MPa) } \\
\text { Without } \\
\text { anchorage }\end{array}$ & $\begin{array}{c}\text { End } \\
\text { anchorage }\end{array}$ & $\begin{array}{c}\text { Full-length } \\
\text { anchorage }\end{array}$ \\
\hline $\begin{array}{l}\text { Smooth } \\
\text { joint }\end{array}$ & 2.91 & 3.75 & 4.02 \\
JRC 0 2 & 3.70 & 4.34 & 5.31 \\
JRC 4 6 & 3.87 & 5.02 & 5.83 \\
JRC 8 10 & 4.63 & 5.69 & 6.35 \\
JRC 12 14 & 5.27 & 6.68 & 7.22 \\
JRC 16 18 & 6.31 & 7.81 & 8.65 \\
\hline
\end{tabular}

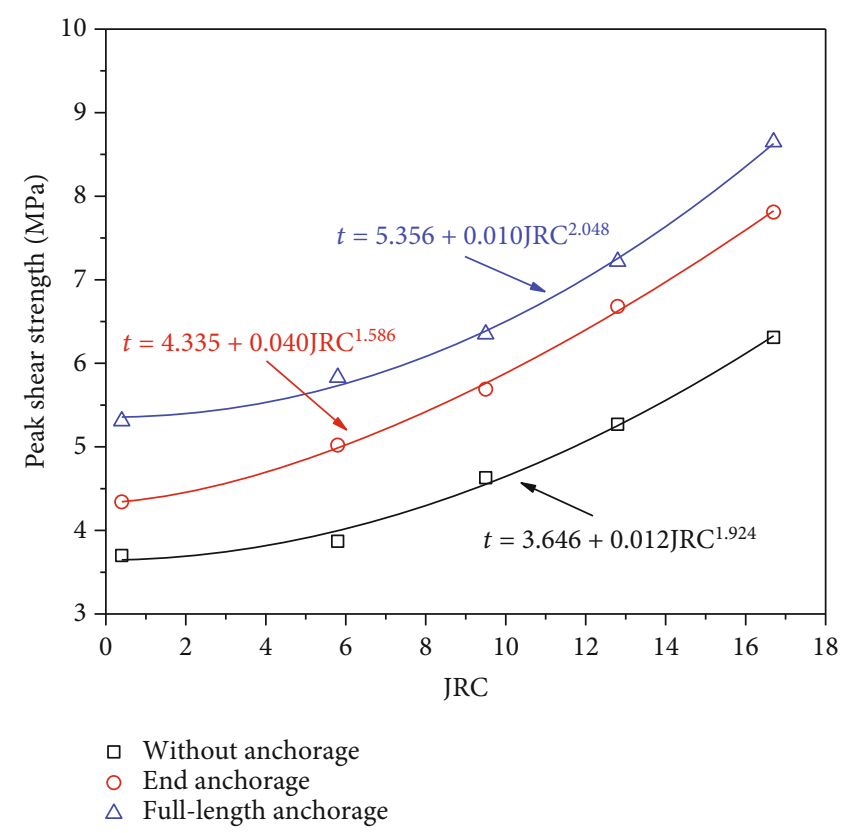

FIGURE 9: Fitting curves of peak shear strength of rough rock-like joints.

joint resists the shear load by cohesive force and friction. After joint is anchored, bolt and joint cooperate to bear shear loads. The shear strength of joint will be enhanced under the action of rock bolt. Therefore, the shear strength peak value of the rock joint significantly increases. However, compared with the full-length anchorage, the mechanical characteristics of the bolt and joint are poorly matched under the end anchorage condition, which is easy to cause the two to be broken one by one, and the anchorage effect is relatively poor.

\subsection{Failure Characteristics}

3.3.1. Joint Surface. The surface damage characteristics of heterogeneous rock joints with different JRC are presented in Figure 10. It can be seen that all structural planes have suffered a certain degree of damage. When the JRC is relatively low, surface damage was primarily caused by wear which is a gradual process of asperity degradation. When the JRC is relatively high, damage occurs more rapid and 


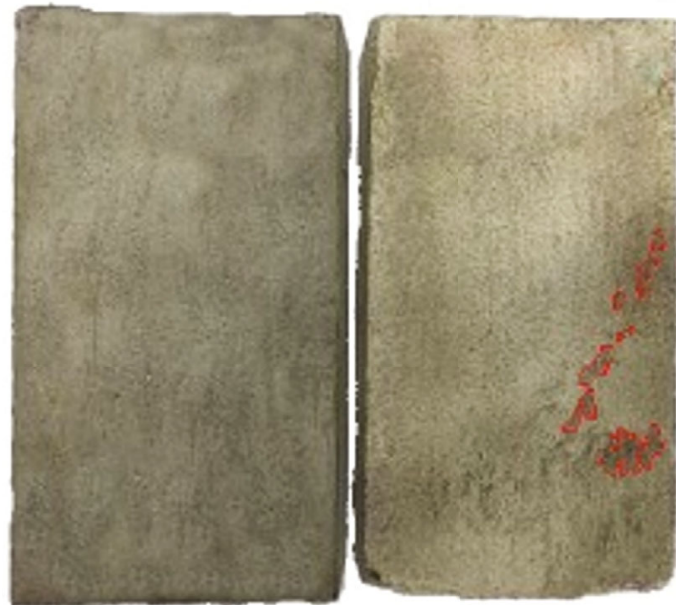

(a)

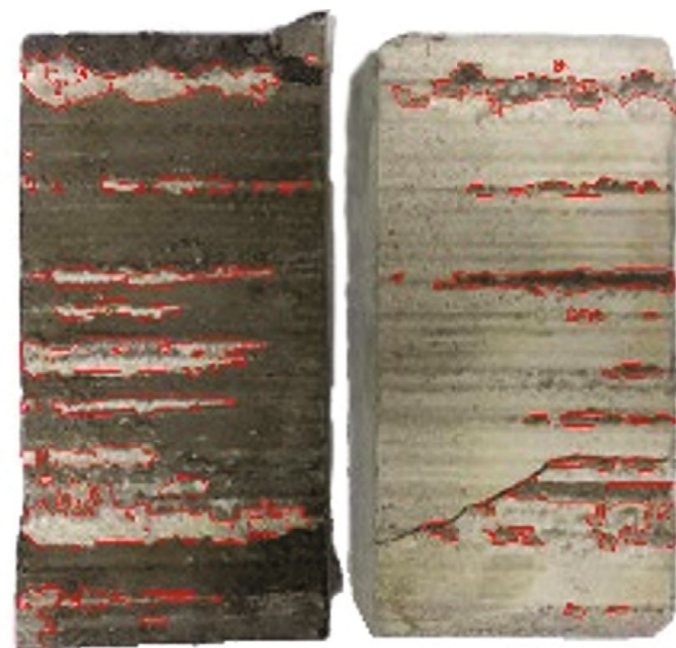

(c)

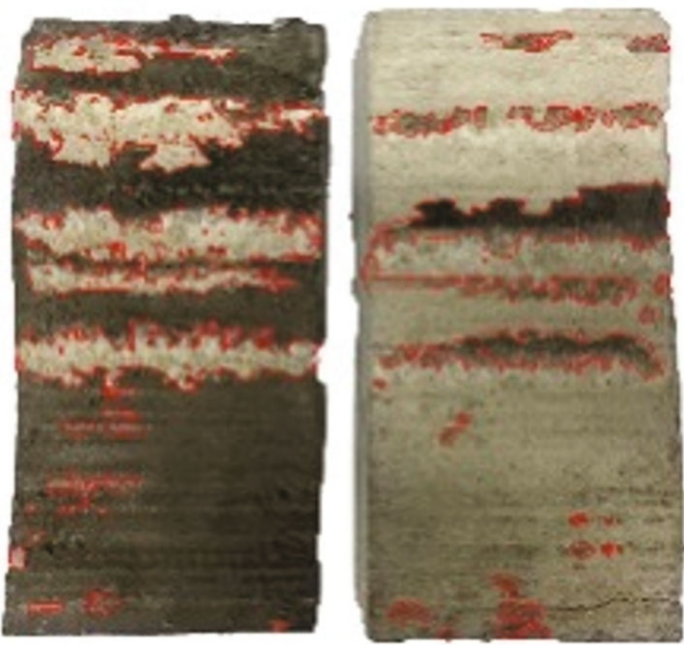

(e)
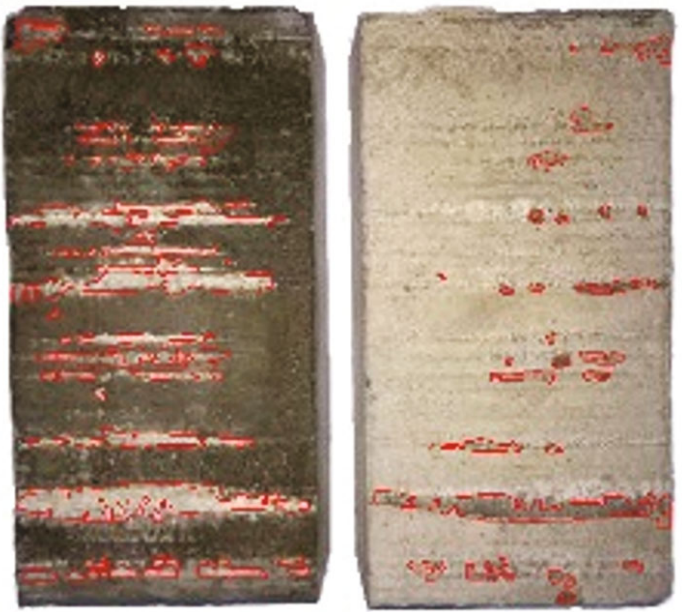

(b)
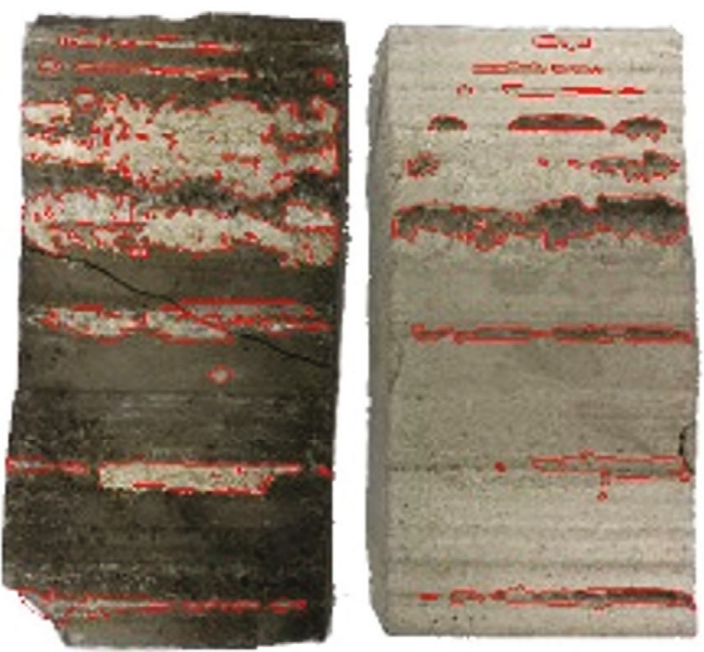

(d)
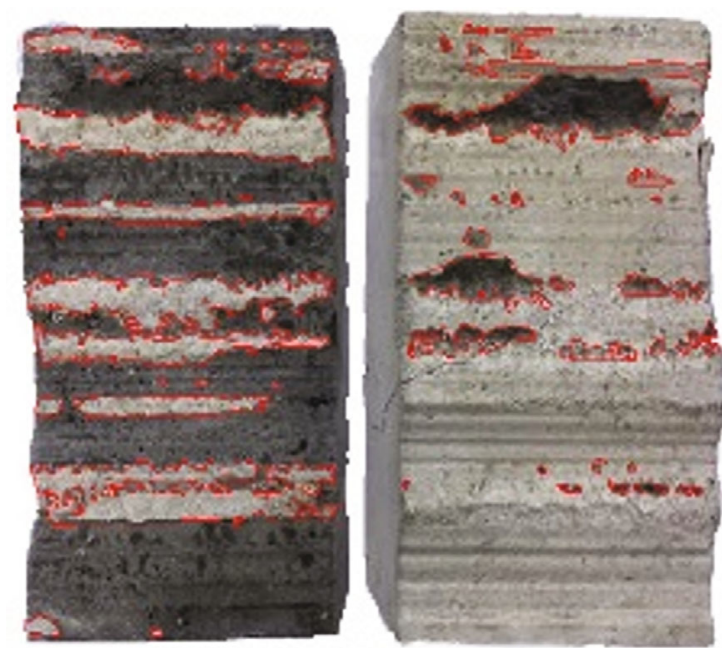

(f)

FIGURE 10: Surface damage characteristics of heterogeneous rock joints: (a) smooth joint; (b) JRC $0 \sim 2$; (c) JRC $4 \sim 6$; (d) JRC $8 \sim 10$; (e) JRC 12 14; (f) JRC 16 18. 
catastrophic (asperities are sheared). With the increase of JRC, the rock debris produced by the wear of the joint surface increases gradually, which indicates that the damage degree of the joint surface increases with the increase of JRC. Meanwhile, different damage patterns were observed on both sides of the heterogeneous rock joint surfaces. The number of rock debris wrapped in red lines varies greatly, and white rock debris is much larger than that of grey rock debris. This indicates that the damage of the joint surface presents obvious heterogeneous characteristics because of the difference of rock mass strength.

The shear strength of the heterogeneous rock joint is closely related to the failure characteristics. When the JRC is relatively low, the bulges of low-strength rock mass bump were largely fractured in the process of mutual movement, while only wear occurred on the surface of high-strength rock mass due to the strength difference. At this time, the low-strength rock mass plays a leading role in the shear strength of the heterogeneous rock joint. With the increase of JRC, the number and fluctuation of bulges of the rock joint will increase correspondingly. High-strength rock can embed in low-strength rock mass, and the damage degree of highstrength rock mass also increases. The trend of shear strength approaching to high-strength rock mass rock joint is more obvious. Therefore, the shear strength of the heterogeneous rock joint lies somewhere in between of the corresponding homogeneous rock joints.

3.3.2. Anchorage System. The characteristics of interface debonding failure of anchorage system, which occurs along the interface between the anchorage agent and rock mass, are presented in Figure 11. It can be seen that the rock bolt has broken off at the anchorage end, and after the rock bolt loses the anchoring force, the rock bolt slides toward the inner part of the specimen when the rock bolts are subjected to axial loading. From the failure characteristics of the bolt section in Figure 11(b), it can be seen that there is a separation between the bolt and the rock mass, and the shear and tensile deformation of the bolt result in a certain angle between the bolt and the hole wall. Correspondingly, the rock mass on the other side will be subjected to greater compressive force, and the closer to the joint, the greater the compressive force. This angle can reflect the strength of anchored rock mass. The lower the strength of rock mass, the higher the degree of failure caused by bolts of rock mass, and the greater the angle. In short, there is a strong pull-out action between the bolt and the rock mass interface. When the rock mass is not strong enough to resist the compressive force of the bolt, the failure mode of the anchorage rock joint is usually the slippage between the bolt and the rock mass.

Figure 12 shows the shear failure pattern of heterogeneous rock joint under end anchorage condition. As can be seen from Figure 12(a), besides the wear of the joint surface, large cracks occur at the anchor hole and the final contact position between the rock mass and the anchor rod, resulting in the breakage of the rock mass. The rock bolt is removed from the low-strength rock mass but still anchored on the high-strength rock mass. Under the action of tensile stress, the rock bolt separates from the low-strength rock block and moves continuously. During the movement of the rock bolt, the rock mass at the anchorage interface is compressed remarkably, resulting in the continuous destruction of the low-strength rock block. Finally, a groove is formed in the rock mass, and a large amount of rock debris is produced on the high-strength rock mass. From the failure pattern of surrounding rock near the anchor hole in Figure 12(b), it can be seen that, with the shear movement, the crushing range of rock mass expands from the anchor hole along the shear direction and finally forms a nearly long elliptical failure zone on the low-strength rock mass. There is no large-scale crushing of rock mass on the high-strength rock mass, and only a small fan-shaped groove is formed. This is because the strength of high-strength rock blocks can resist the extrusion effect of rock bolt. The reason for the above failure modes is that the horizontal shear force exerted by the testing machine on the rock mass with anchored joints results in a large compressive force on the interface between the bolt and the hole wall near the joint plane (about 3 times the diameter of the bolt). Therefore, the bolt hole wall is crushed, and local failure occurs near the joint surface.

Figure 13 shows the shear failure pattern of heterogeneous rock joint under full-length anchorage condition. As can be seen from Figure 13(a), the failure mode of the joint surface under full-length anchorage is very similar to that under end anchorage, so it is not introduced too much. From the failure pattern of surrounding rock near the anchor hole in Figure 13(b), it can be seen that, with the shear movement, the crushing range of rock mass expands from the anchor hole along the shear direction and finally forms a crescentshaped failure zone and produces a large number of rock debris on the low-strength rock mass. There is no crushing of rock mass on the high-strength rock mass. This is because the strength of high-strength rock blocks can resist the extrusion effect of rock bolt. In addition, the anchorage agent on the side of the bolt is damaged by tensile force and detached from the rock bolt.

Figure 14 shows the comparison of crushing failure modes of rock mass under different anchorage conditions. Comparing with the failure modes of end anchorage and full-length anchorage, it can be seen that the failure area of end anchorage is approximately long ellipse, and the failure area of full-length anchorage is approximately crescent. This is because, compared with end anchorage, the extrusion force caused by the anchorage bolt will diffuse around the anchorage agent when full-length anchorage. Therefore, the extrusion stress produced on the rock mass is relatively small and will not cause partial continuous damage.

3.3.3. Rock Bolt. The deformation characteristic of bolt after shear test can well reflect the stress characteristics of bolt during shear test and its anchoring mechanism to rock joint. The deformation characteristics of rock bolts after shear test are presented in Figure 15. It can be seen that the bolts have not been sheared, but in a considerable section (about 3-4 times the diameter of the bolts), there have been a significant shear deformation, resulting in varying degrees of near " $\mathrm{S}$ " shaped bending. But the length of $\mathrm{Lm}$ in vertical direction did not change significantly. This is because under the action 


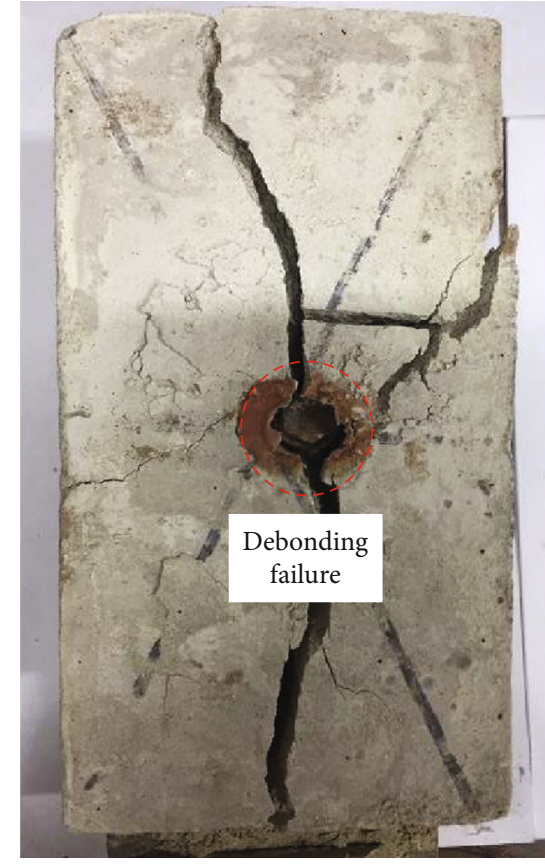

(a)

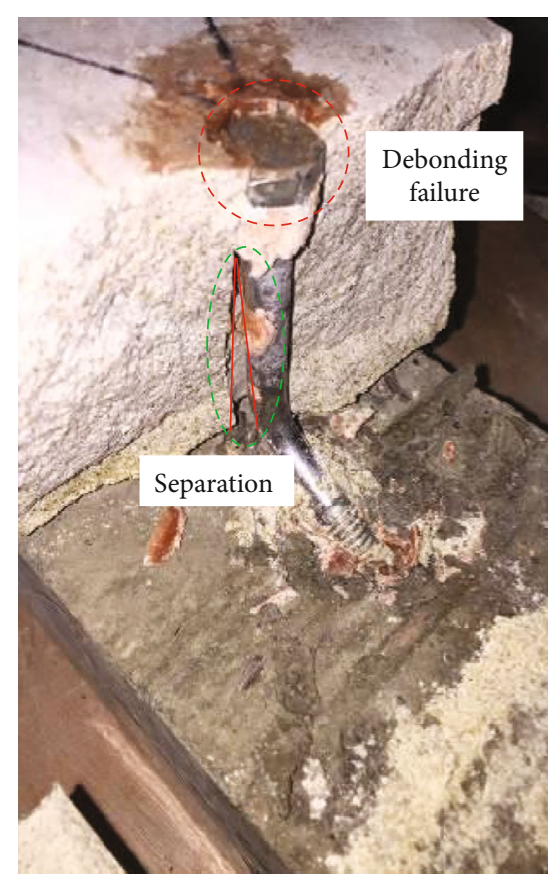

(b)

FIGURE 11: Characteristics of interface debonding failure of anchorage system: (a) global; (b) local.

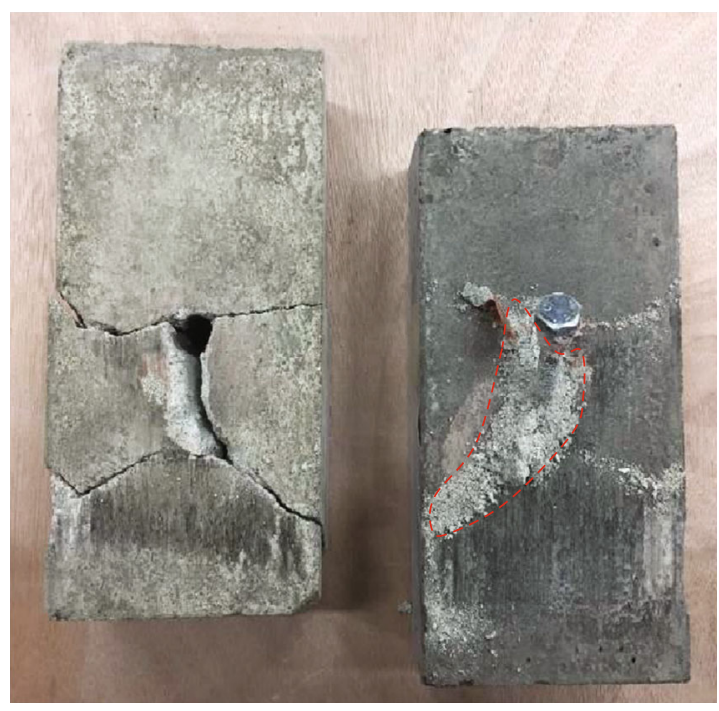

(a)

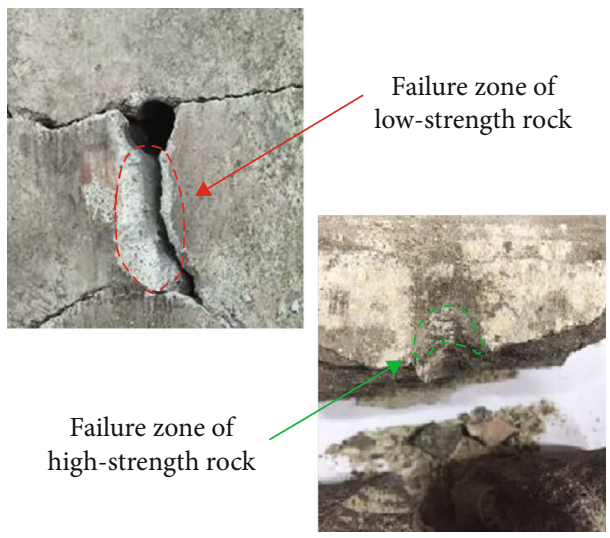

(b)

FIGURE 12: Shear failure pattern of heterogeneous rock joint under end anchorage condition: (a) global; (b) local.

of shear force, the bolt body produced both axial and transverse deformation. The deformation was superimposed on the "S" shape. In addition, the bond between rock bolt and anchorage agent is relatively complete after the failure of anchorage system, and the failure mode is mainly the breakage of anchorage agent and rock mass.

The local deformation characteristics of rock bolts after shear test are presented in Figure 16. It can be seen that the bolts can be divided into tension zones, shear zones, and compression zones after large deformation, no matter end anchorage or full-length anchorage. On the two sides of the joint surface, there are approximately symmetrical stretching zones and compression zones on the rock bolts. There is a shear-tension zone near the joint surface, where the rock bolt is easily damaged by the combined action of shear stress and tensile stress. In addition, the anchorage agent on the fulllength rock bolt ruptures under the action of tensile force and then separates from the rock bolt, resulting in two symmetrical tensile failure zones.

In a word, the shear dislocation between the upper and lower rock blocks under shear load results in the interaction between the bolt and surrounding media. It causes the 


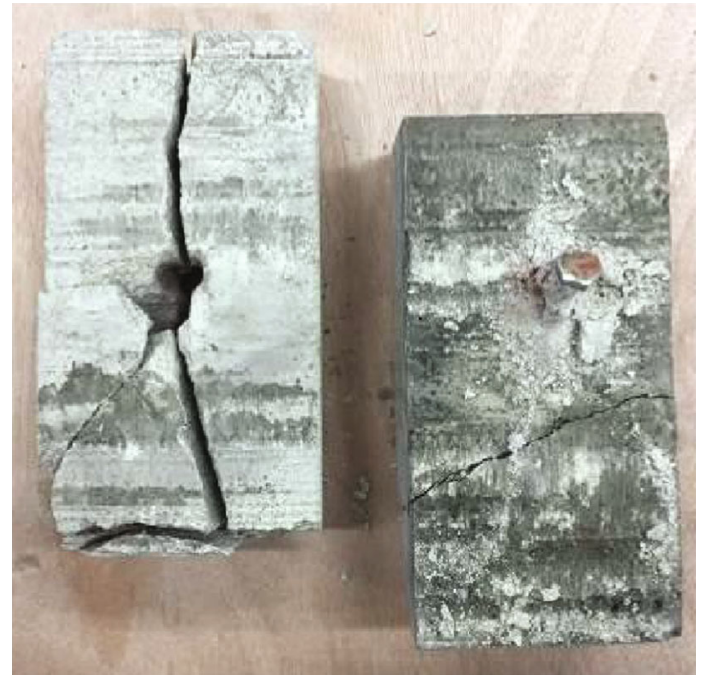

(a)

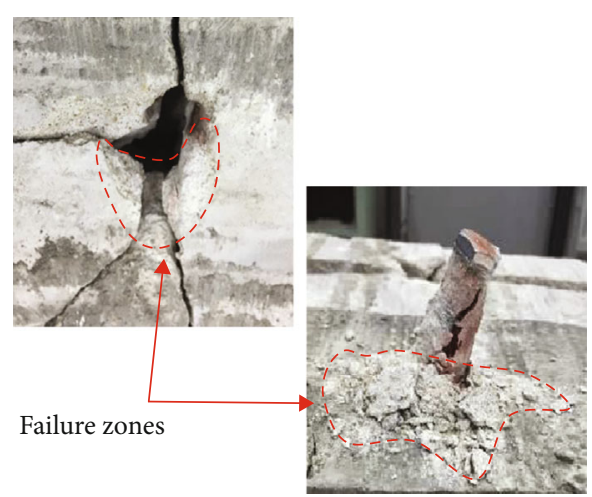

(b)

FIGURE 13: Shear failure pattern of heterogeneous rock joint under full-length anchorage condition: (a) global; (b) local.

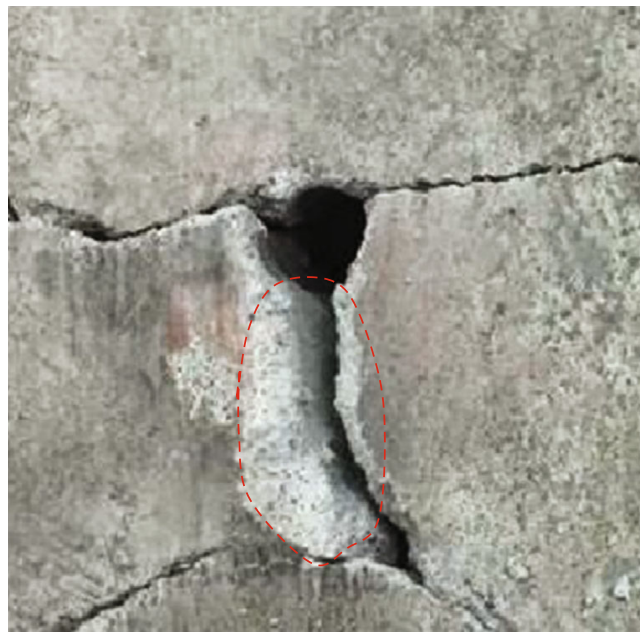

(a)

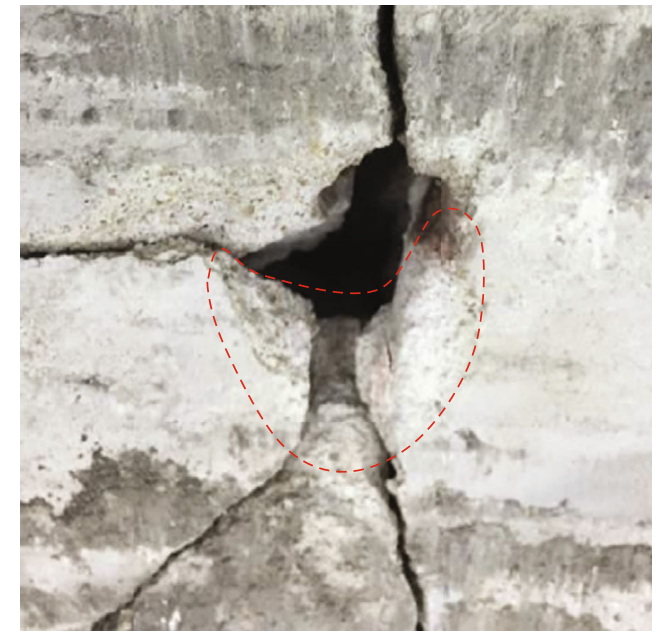

(b)

FIGURE 14: Comparison of rock mass failure pattern: (a) end anchorage; (b) full-length anchorage.

bending deformation of the rock bolt, which leads to the production of shear stress and bending moment inside the anchor joint. In addition, due to the dilatancy effect of the joint, the axial stress also occurs in the bolt, and the bending moment of the bolt will also contribute to the axial stress. Therefore, the stress state of bolt near the joint is very complicated.

\section{Discussion}

From the above analysis, it is clear that the rock bolt has a significant impact on the shear behavior of the anchorage system, which not only increases the shear strength of the rock joint but also causes the local damage of the anchorage system. The failure modes of the anchorage rock joints studied above are mainly anchor interface debonding and rock block crushing, and the failure mode of rock bolt shear fracture is not occurred. However, bolt shear fracture is also a common failure mode of anchorage rock joints. Hence, high-strength hard rock (artificial corundum, uniaxial compressive strength $101.65 \mathrm{MPa}$ ) is selected to further study the shear failure characteristics of anchorage rock joints. The experimental methods adopted are the same as before.

The shear failure mode of high-strength hard anchorage joint is presented in Figure 17. It can be seen that the rock bolt is still in good bond with the rock block, and there is no large-scale shear failure; only local shear deformation of rock bolt occurs near the joint surface. Moreover, the rock bolt broke off at the junction with the joint surface. From the overall shear failure pattern of the joint in Figure 17(a), it can be seen that the rock mass on both sides of the joint has obvious wear damage, but the rock mass kept intact without breaking. The bolt has occurred shear fracture along the joint when the shear displacement reaches a small value. From the failure pattern of surrounding rock near the 


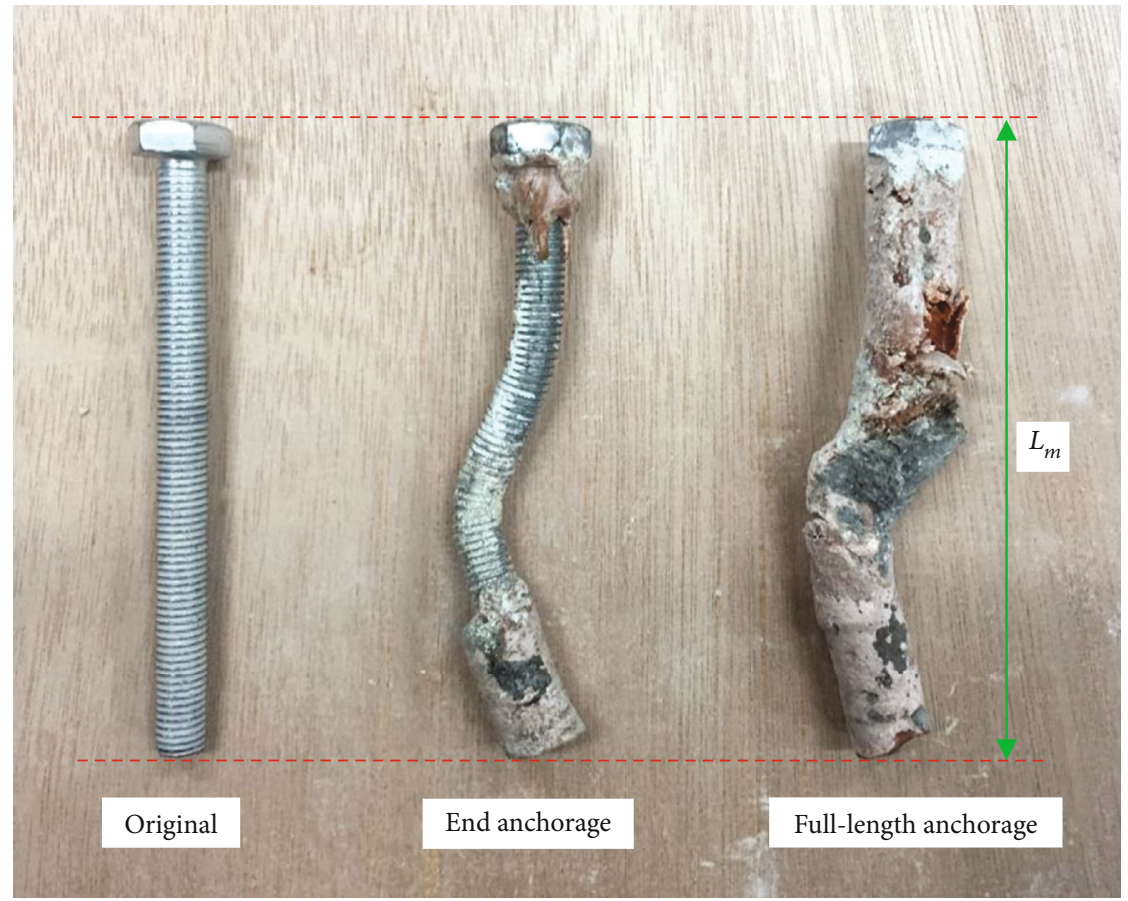

FIGURE 15: Bolt shape after shear test.

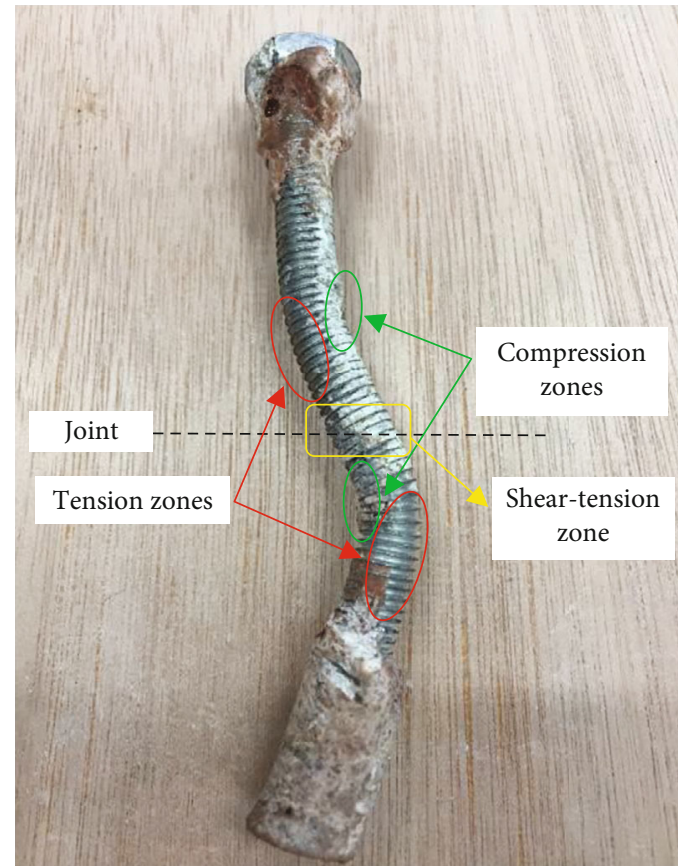

(a)

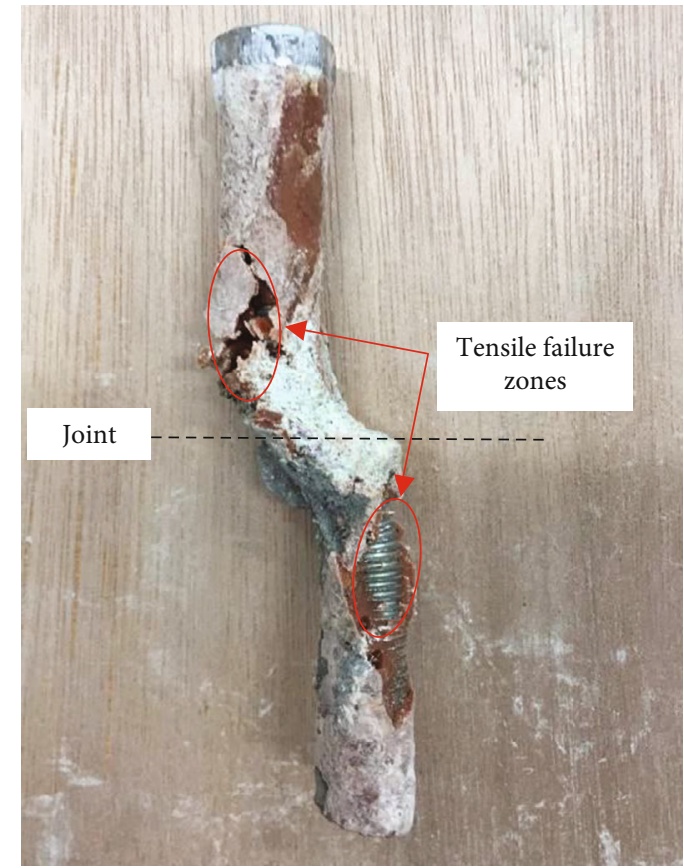

(b)

Figure 16: Deformation characteristics of blots after shear: (a) end anchorage; (b) full-length anchorage.

anchorage interface in Figure 17(b), it can be seen that the crescent-shaped compressive failure zone and void zone appeared along the shear direction of the specimen on both sides of the rock bolt, and they are basically symmetrical distribution. The rock mass near the anchorage interface does not cause great damage because the rock mass is strong enough to resist the compression of the rock bolt. Generally, in the abovementioned weak rock joints, the part of rock bolt can occur deformation increases with the compression failure of the rock mass. The bolt can produce enough elongation to adapt to the shear deformation and avoid shear fracture. However, compared with the weak rock joints, under the restriction of high-strength hard rock, only a small part of rock bolt can occur deformation near the joint 


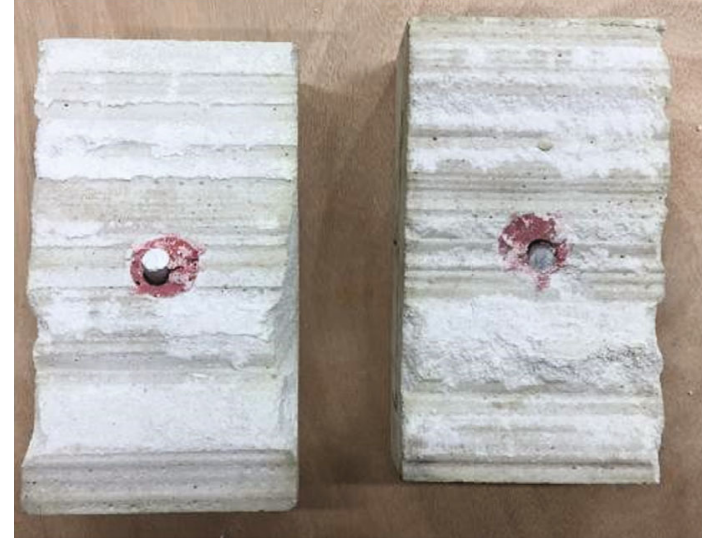

(a)

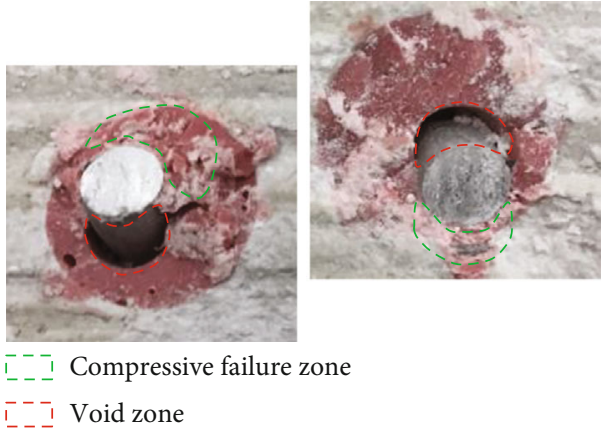

(b)

FIGURE 17: Shear failure mode of high-strength hard anchorage joint: (a) overall shear failure pattern; (b) failure pattern of surrounding rock near the anchorage interface.

surface. So, the bolt can not produce enough elongation to adapt to the shear deformation of the anchorage system. Excessive local deformation leads to shear fracture of rock bolt.

By comprehensive comparison of the failure mode of different anchorage system, it can be seen that the result is influenced by the deformability of the surrounding rock, and interaction occurs between various media in the anchorage system. Actually, the strength and stiffness of the bolt, anchorage conditions, and properties of surrounding rock will have a significantly effect on anchorage effect and may cause different failure characteristics of anchorage system. Therefore, although it can improve the shear strength of jointed rock mass, it is not necessary to increase the strength and stiffness of the bolts indefinitely. The damage of the rock bolt to rock mass should be considered when the jointed rock mass is reinforced with rock bolts, so as to realize the coupling support. This will be of great significance in guiding the design of anchored support for jointed rock mass.

\section{Conclusions}

In this paper, a shear test method for bolted heterogeneous rock joints is developed and employed to perform experimental investigations on shear behavior of bolted heterogeneous rock joints. The influences of JRC and anchorage conditions are systematically observed based on the experimental results. The conclusions can be drawn as follows:

(1) The morphological characteristics of shear stressshear displacement curves of full-length anchorage joints have higher ultimate load, faster resistance increase, longer plastic strength stage, and stronger residual shear resistance than the without anchorage and end anchorage joints

(2) The shear strengths of rock-like joints increase with the increase of JRC, showing exponential growth. Under the same roughness, the shear strengths from the large to the small are full-length anchorage, end anchorage condition, and without anchorage. Compared with the full-length anchorage, the mechanical characteristics of the bolt and joint are poorly matched under the end anchorage condition, which is easy to cause the two to be broken one by one, and the anchorage effect is relatively poor

(3) The surface damage of heterogeneous rock joints increases with the increase of JRC and presents obvious heterogeneous characteristics. The shear strength of the heterogeneous rock joint lies somewhere in between of the corresponding homogeneous rock joints

(4) Compared with end anchorage, the extrusion force caused by the anchorage bolt will diffuse around the anchorage agent when full-length anchorage. Therefore, the extrusion stress produced on the rock mass is relatively small and will not cause partial continuous damage

(5) The shear dislocation between the blocks under shear load results in the interaction between the bolt and surrounding. Under the action of shear force, the bolt body produced both axial and transverse deformation, which leads to the breakage of anchorage agent and rock mass

(6) The rock bolt has a significant impact on the shear behavior of the anchorage system. The damage of the rock bolt to rock mass should be considered when the jointed rock mass is reinforced with rock bolts, so as to realize the coupling support

\section{Data Availability}

The data used to support the findings of this study are available from the corresponding author upon request.

\section{Conflicts of Interest}

The authors declare no conflict of interest. 


\section{Acknowledgments}

This work is supported by the Shandong Provincial Natural Science Foundation (Nos. ZR2019BEE065 and ZR2020QE120) and the Shandong University of Science and Technology Graduate Innovation Fund (No. sdkdyc190231).

\section{References}

[1] A. K. Shrivastava and K. S. Rao, "Physical modeling of shear behavior of infilled rock joints under CNL and CNS boundary conditions," Rock Mechanics and Rock Engineering, vol. 51, no. 1, pp. 101-118, 2018.

[2] Z. G. Tao, C. Zhu, M. C. He, and M. Karakus, "A physical modeling-based study on the control mechanisms of Negative Poisson's ratio anchor cable on the stratified toppling deformation of anti-inclined slopes," International Journal of Rock Mechanics and Mining Sciences, vol. 138, article 104632, 2021.

[3] C. Zhu, M. C. He, M. Karakus, X. H. Zhang, and Z. G. Tao, "Numerical simulations of the failure process of anaclinal slope physical model and control mechanism of negative Poisson's ratio cable," Bulletin of Engineering Geology and the Environment, vol. 80, no. 4, pp. 3365-3380, 2021.

[4] Y. Wang, W. K. Feng, R. L. Hu, and C. H. Li, "Fracture evolution and energy characteristics during marble failure under triaxial fatigue cyclic and confining pressure unloading (FC-CPU) conditions," Rock Mechanics and Rock Engineering, vol. 54, no. 2, pp. 799-818, 2021.

[5] B. Li, R. Bao, Y. Wang, R. Liu, and C. Zhao, "Permeability evolution of two-dimensional fracture networks during shear under constant normal stiffness boundary conditions," Rock Mechanics and Rock Engineering, vol. 54, no. 1, pp. 409-428, 2021.

[6] Q. Wang, H. K. Gao, B. Jiang, S. C. Li, M. C. He, and Q. Qin, "In-situ test and bolt-grouting design evaluation method of underground engineering based on digital drilling," International Journal of Rock Mechanics and Mining Sciences, vol. 138, article 104575, 2021.

[7] Q. Wang, Q. Qin, B. Jiang et al., "Mechanized construction of fabricated arches for large-diameter tunnels," Automation in Construction, vol. 124, article 103583, 2021.

[8] S. L. Su, Y. Du, J. F. Zhu, L. Zhang, Z. L. Zhao, and B. Meng, "Numerical study on bearing behavior of layered rock mass for deep roadway," Journal of Mining and Strata Control Engineering, vol. 2, no. 1, article 013002, 2020.

[9] C. Zhang, W. D. Song, J. X. Fu, Y. Li, and K. C. Zhang, “Technology for roadway management of fractured rock masses in a submarine gold mine," Journal of Mining and Strata Control Engineering, vol. 2, no. 3, article 033039, 2020.

[10] J. K. Li and H. Wang, "Ground support of interbedded rock roof in a deep roadway with fully-anchored cables," Journal of Mining and Strata Control Engineering, vol. 2, no. 3, article 033036, 2020.

[11] A. Li, F. Dai, Y. Liu, H. B. Du, and R. C. Jiang, "Dynamic stability evaluation of underground cavern sidewalls against flexural toppling considering excavation-induced damage," Tunnelling and Underground Space Technology, vol. 112, p. 103903, 2021.

[12] C. J. Jia, W. Y. Xu, R. B. Wang, S. S. Wang, and Z. N. Lin, "Experimental investigation on shear creep properties of undisturbed rock discontinuity in Baihetan Hydropower
Station," International Journal of Rock Mechanics and Mining Sciences, vol. 104, pp. 27-33, 2018.

[13] H. K. Singh and A. Basu, "A comparison between the shear behavior of 'real' natural rock discontinuities and their replicas," Rock Mechanics and Rock Engineering, vol. 51, no. 1, pp. 329-340, 2018.

[14] S. M. M. Niktabar, K. S. Rao, and A. K. Shrivastava, "Effect of rock joint roughness on its cyclic shear behavior," Journal of Rock Mechanics and Geotechnical Engineering, vol. 9, no. 6, pp. 1071-1084, 2017.

[15] Y. Li, H. Zhou, L. Zhang, W. Zhu, S. Li, and J. Liu, "Experimental and numerical investigations on mechanical property and reinforcement effect of bolted jointed rock mass," Construction and Building Materials, vol. 126, pp. 843-856, 2016.

[16] N. Bahrani and J. Hadjigeorgiou, "Explicit reinforcement models for fully-grouted rebar rock bolts," Journal of Rock Mechanics and Geotechnical Engineering, vol. 9, no. 2, pp. 267-280, 2017.

[17] X. Li, J. Nemcik, A. Mirzaghorbanali, N. Aziz, and H. Rasekh, "Analytical model of shear behaviour of a fully grouted cable bolt subjected to shearing," International Journal of Rock Mechanics and Mining Sciences, vol. 80, pp. 31-39, 2015.

[18] B. Zhang, S. Li, K. Xia et al., "Reinforcement of rock mass with cross-flaws using rock bolt," Tunnelling and Underground Space Technology, vol. 51, pp. 346-353, 2016.

[19] L. P. Srivastava and M. Singh, "Empirical estimation of strength of jointed rocks traversed by rock bolts based on experimental observation," Engineering Geology, vol. 197, pp. 103-111, 2015.

[20] H. Jalalifar, N. Aziz, and M. Hadi, “The effect of surface profile, rock strength and pretension load on bending behaviour of fully grouted bolts," Geotechnical and Geological Engineering, vol. 24, no. 5, pp. 1203-1227, 2006.

[21] B. Forbes, N. Vlachopoulos, A. J. Hyett, and M. S. Diederichs, "A new optical sensing technique for monitoring shear of rock bolts," Tunnelling and Underground Space Technology, vol. 66, pp. 34-46, 2017.

[22] Y. Chen and C. C. Li, "Performance of fully encapsulated rebar bolts and D-Bolts under combined pull- and-shear loading," Tunnelling and Underground Space Technology, vol. 45, pp. 99-106, 2015.

[23] H. Kang, Y. Wu, F. Gao, J. Lin, and P. Jiang, "Fracture characteristics in rock bolts in underground coal mine roadways," International Journal of Rock Mechanics and Mining Sciences, vol. 62, pp. 105-112, 2013.

[24] H. Rasekh, A. Mirzaghorbanali, J. Nemcik, N. Aziz, and X. Li, "A new equation for the shear strength of cable bolts incorporating the energy balance theory," Geotechnical and Geological Engineering, vol. 35, no. 4, pp. 1529-1548, 2017.

[25] H. Kang, Y. Wu, F. Gao et al., "Mechanical performances and stress states of rock bolts under varying loading conditions," Tunnelling and Underground Space Technology, vol. 52, pp. 138-146, 2016.

[26] S. Ma, Z. Zhao, J. Peng, and Y. Gui, "Analytical modeling of shear behaviors of rockbolts perpendicular to joints," Construction and Building Materials, vol. 175, pp. 286-295, 2018.

[27] L. Li, P. C. Hagan, S. Saydam, B. Hebblewhite, and Y. Li, "Parametric study of rockbolt shear behaviour by double shear test," Rock Mechanics and Rock Engineering, vol. 49, no. 12, pp. 4787-4797, 2016. 
[28] Y. Chen, P. Cao, K. Zhou, and Y. Teng, "Relationship between loading angle and displacing angle in steel bolt shearing," Transactions of Nonferrous Metals Society of China, vol. 27, no. 4, pp. 876-882, 2017.

[29] J. Liu, H. Yang, H. Wen, and X. Zhou, “Analytical model for the load transmission law of rock bolt subjected to open and sliding joint displacements," International Journal of Rock Mechanics and Mining Sciences, vol. 100, pp. 1-9, 2017.

[30] X. Li, N. Aziz, A. Mirzaghorbanali, and J. Nemcik, "Comparison of the shear test results of a cable bolt on three laboratory test apparatuses," Tunnelling and Underground Space Technology, vol. 61, pp. 82-89, 2017.

[31] X. Li, N. Aziz, A. Mirzaghorbanali, and J. Nemcik, "Behavior of fiber glass bolts, rock bolts and cable bolts in shear," Rock Mechanics and Rock Engineering, vol. 49, no. 7, pp. 27232735, 2016.

[32] G. Grasselli, "3D behaviour of bolted rock joints: experimental and numerical study," International Journal of Rock Mechanics and Mining Sciences, vol. 42, no. 1, pp. 13-24, 2005.

[33] H. Jalalifar and N. Aziz, "Experimental and 3D numerical simulation of reinforced shear joints," Rock Mechanics and Rock Engineering, vol. 43, no. 1, pp. 95-103, 2010.

[34] C. H. Liu and Y. Z. Li, "Analytical study of the mechanical behavior of fully grouted bolts in bedding rock slopes," Rock Mechanics and Rock Engineering, vol. 50, no. 9, pp. 24132423, 2017.

[35] M. Bahaaddini, "Effect of boundary condition on the shear behaviour of rock joints in the direct shear test," Rock Mechanics and Rock Engineering, vol. 50, no. 5, pp. 1141-1155, 2017.

[36] G. Wang, Y. Zhang, Y. Jiang, S. Wang, and W. Jing, "Macromicro failure mechanisms and damage modeling of a bolted rock joint," Advances in Materials Science and Engineering, vol. 2017, Article ID 1627103, 15 pages, 2017.

[37] B. Meng, H. Jing, S. Yang, Y. Wang, and B. Li, "Experimental study on the shear behavior of bolted concrete blocks with oblique shear test," Advances in Civil Engineering, vol. 2018, Article ID 7281218, 8 pages, 2018.

[38] X. Wu, Y. Jiang, and B. Li, "Influence of joint roughness on the shear behaviour of fully encapsulated rock bolt," Rock Mechanics and Rock Engineering, vol. 51, no. 3, pp. 953-959, 2018.

[39] G. Wang, Y. Zhang, Y. Jiang et al., "Shear behaviour and acoustic emission characteristics of bolted rock joints with different roughnesses," Rock Mechanics and Rock Engineering, vol. 51, no. 6, pp. 1885-1906, 2018.

[40] J. G. Gutiérrez-Ch, S. Senent, S. Melentijevic, and R. Jimenez, "Distinct element method simulations of rock-concrete interfaces under different boundary conditions," Engineering Geology, vol. 240, pp. 123-139, 2018.

[41] H. M. Tian, W. Z. Chen, D. S. Yang, and J. P. Yang, "Experimental and numerical analysis of the shear behaviour of cemented concrete-rock joints," Rock Mechanics and Rock Engineering, vol. 48, no. 1, pp. 213-222, 2015.

[42] H. Mouzannar, M. Bost, M. Leroux, and D. Virely, "Experimental study of the shear strength of bonded concrete-rock interfaces: surface morphology and scale effect," Rock Mechanics and Rock Engineering, vol. 50, no. 10, pp. 26012625, 2017.

[43] H. Lin, M. Wang, and W. Xu, "Shear behaviors of the binary structural plane," Geotechnical and Geological Engineering, vol. 36, pp. 939-948, 2017.
[44] Y. Jiang, Y. Chen, X. Cheng et al., "Experimental study on shear behavior and acoustic emission characteristics of nonpersistent joints," Geofluids, vol. 2020, Article ID 8815467, 10 pages, 2020.

[45] G. Wang, X. Zhang, Y. Jiang, X. Wu, and S. Wang, "Ratedependent mechanical behavior of rough rock joints," International Journal of Rock Mechanics and Mining Sciences, vol. 83, pp. 231-240, 2016.

[46] X. Wu, Y. Jiang, B. Gong, T. Deng, and Z. Guan, "Behaviour of rock joint reinforced by energy-absorbing rock bolt under cyclic shear loading condition," International Journal of Rock Mechanics and Mining Sciences, vol. 110, pp. 88-96, 2018.

[47] N. R. Barton and V. Choubey, "The shear strength of rock joints in theory and practice," Rock Mechanics, vol. 10, no. 12, pp. 1-54, 1977. 